\title{
How to Define Successful Stocking of Florida's Freshwater Recreational Fisheries ${ }^{1}$
}

\author{
Edward V. Camp, Rick Stout, Nick Trippel, Jon Fury, Stasey Whichel, and Kai Lorenzen²
}

\section{Abstract}

Stocking, a common and popular but intensive option for managing and improving recreational fisheries, has a long history of use in Florida. To operate efficiently, fisheries management agencies must evaluate the success or failure of stocking programs. Researchers and management agencies have conducted years of research to better understand how stocking has affected freshwater fish and fisheries, but there is still no agreed-upon definition of successful stocking. This means that determining how "successful" stocking has been in Florida overall is challenging if not impossible. This document reviews recent scientific literature to describe the benefits of stocking and the potential drawbacks and thus to create useful definitions of stocking success. It also proposes some metrics for evaluating stocking success specifically tailored for Florida. We describe how successful stocking programs require explicit and measurable management objectives. For Florida's recreational fisheries, objectives may often focus on socioeconomic metrics, such as the number of active anglers, their satisfaction with the fishing experience, and their overall attitudes and perceptions of management, as well as biological measures like the survival or growth of the stocked fish themselves. We also describe how stocking, if well-planned, can achieve even broader research and management goals of increasing understanding of how fisheries function-both biologically and socioeconomically.

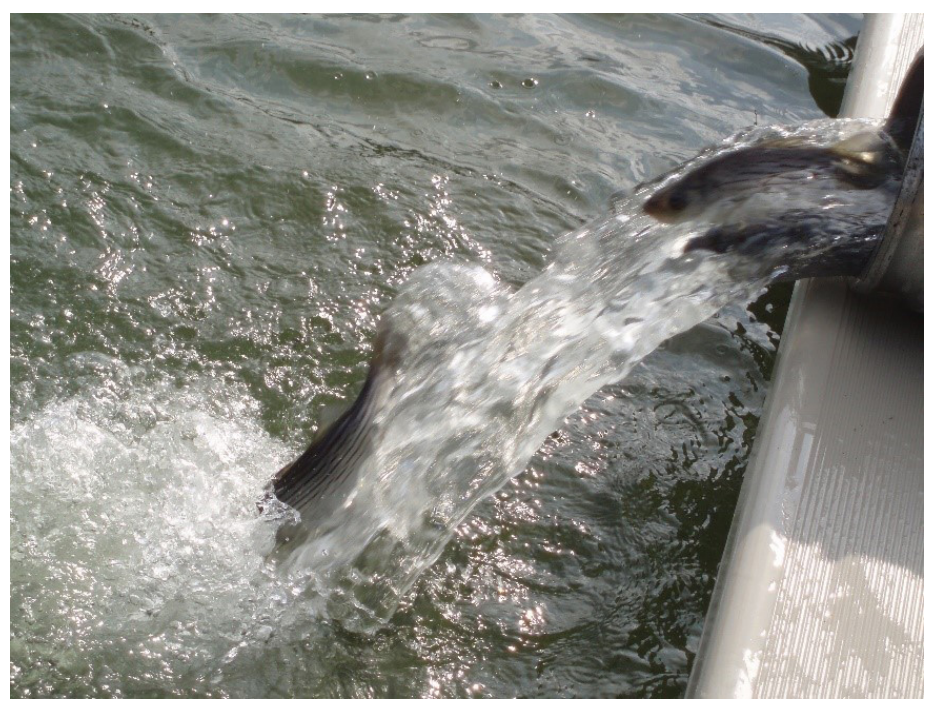

Figure 1. How "successful" will this hybrid striped bass stocking be? Credits: Rick Stout

\section{Introduction: What is stocking, and why should we care about evaluating it?}

One of the oldest and most popular ways to manage recreational fisheries in North America is stock enhancement-the addition of hatchery-raised fish into fishing waters (Figure 1) (Lorenzen 2005; Camp et al. 2013). Usually, stocking is conducted by management agencies to increase the abundance of fish that anglers can catch. The

1. This document is FA216, one of a series of the School of Forest Resources and Conservation, Program in Fisheries and Aquatic Sciences, UF/IFAS Extension. Original publication date August 2019. Visit the EDIS website at https://edis.ifas.ufl.edu for the currently supported version of this publication.

2. Edward V. Camp, assistant professor, School of Forest Resources and Conservation; Rick Stout, director of the Florida Bass Conservation Center, Division of Freshwater Fisheries Management, Florida Fish and Wildlife Conservation Commission; Nick Trippel, research administrator I, Florida Institute of Fish and Wildlife Research, Florida Fish and Wildlife Conservation Commission; Jon Fury, director, Division of Freshwater Fisheries Management, Florida Fish and Wildlife Conservation Commission; Stasey Whichel, deputy director, Division of Freshwater Fisheries Management, Florida Fish and Wildlife Conservation Commission; and Kai Lorenzen, professor, School of Forest Resources and Conservation; UF/IFAS Extension, Gainesville, FL 32611.

The Institute of Food and Agricultural Sciences (IFAS) is an Equal Opportunity Institution authorized to provide research, educational information and other services

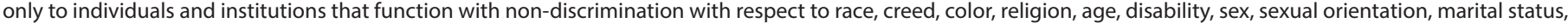


U.S. Department of Agriculture, UF/IFAS Extension Service, University of Florida, IFAS, Florida A \& M University Cooperative Extension Program, and Boards of County Commissioners Cooperating. Nick T. Place, dean for UF/IFAS Extension. 


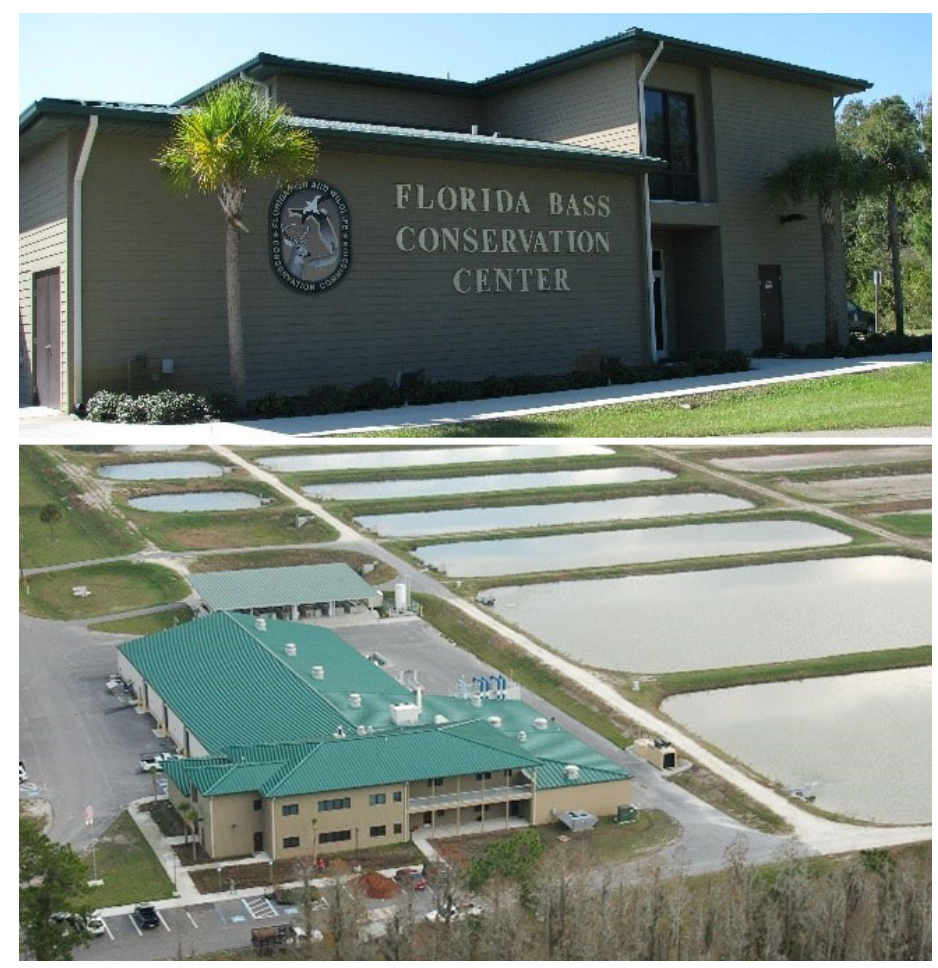

Figure 2. The Florida Bass Conservation Center, where nearly all of the fish for freshwater recreational stocking are raised.

Credits: Rick Stout

goal is that this will increase angler catches and eventually lead to increased fishing trips and greater angler satisfaction with fishing and management. Maintaining stocking programs requires considerable agency resources, however, especially given the time and effort required to collect, maintain, and spawn brood stock, raise juvenile fish to appropriate sizes, and transport fish to waters for stocking. Since management agencies have limited hatchery space, personnel, and financial budgets, there is a limit to the number, size, and species of fish that can be stocked each year. Efficiently allocating agency resources requires good decision making about where and when to stock fish. The goal is to stock in a way that increases the overall stocking "success."

Defining the success of stocking has proven challenging, despite the long history of stocking and stocking-related research in Florida. Stocking is conducted by the Florida Fish and Wildlife Conservation Commission (FWC) Division of Freshwater Fisheries Management (DFFM) in close cooperation with the FWC Fish and Wildlife Research Institute (FWRI). The stocked fish are reared at two state hatcheries, with most currently produced at the Richloam Florida Bass Conservation Center (Figure 2). For decades, FWC has stocked millions of Florida largemouth bass, channel catfish, sunfish (i.e., Lepomis species such as bluegill), and striped bass and white bass hybrids called sunshine bass (genus Morone) into waters throughout the state (Figure 3). Much research has been conducted to study stocked fish survival rates and how survival depends on how the fish were raised in the hatchery, their sizes at the time of release, and the locations at which they were released into the wild (Figure 4). While historical stocking has not been extensively evaluated in terms of effects on overall fish populations, recent stocking, especially of largemouth bass, has been most commonly assessed in terms of "percent contribution."

Percent contribution refers to the ratio of stocked fish to all fish (stocked plus wild) of that species and year class in a water body. It is measured by sampling waters that have been stocked and calculating, for example, the proportion of young (born that year) largemouth bass that came from hatcheries. However, because percent contribution is a ratio, this metric will change if greater or lesser numbers of wild fish are sampled - which may be completely unrelated to stocking. This can make it difficult to interpret "success" of stocking from percent contribution. For example, percent contribution could be very different in the same lake in different years, depending on either the survival of stocked fish or the highly variable abundance of wild fish (Walters and Martell 2004). This makes it difficult to use percent contribution to evaluate even the biological "success" of stocking. For that reason, management agencies are increasingly interested in gauging the effects of stocking by directly measuring the survival rates of stocked fish (Pouder et al. 2010). More importantly, biological changes are only some effects of stocking that are important to fisheries managers. Often, the ultimate goals of stocking relate to socioeconomic measures, like fishing license sales, total fishing trips, or angler satisfaction. What is needed is a useful definition of stocking success that management agencies can use to compare different types of stocking and that can support decision making about how to use scarce agency resources to best sustain and enhance freshwater recreational fisheries in Florida.

\section{Approach: Information Provided in This Publication}

This publication is intended to provide information useful to management agencies that make stocking decisions, and it also can help recreational anglers and the public understand how stocking affects fisheries. The work has two objectives: (1) describe what is necessary to define successful stocking, and (2) suggest metrics that might be useful for defining stocking success in Florida's recreational fisheries. After providing this information, we describe how stocking plans can be developed to increase the benefits of stocking. 


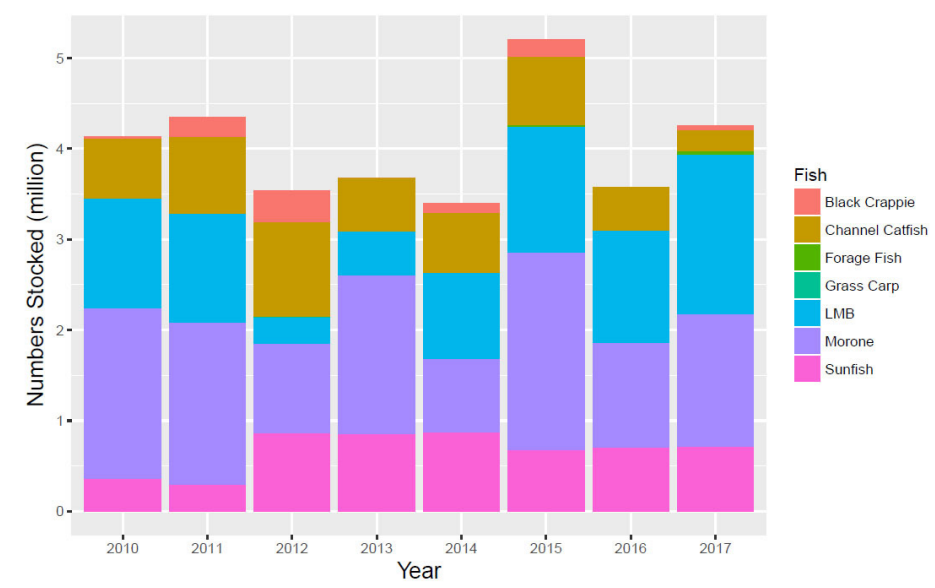

Figure 3. Cumulative numbers of fish stocked since 2010. In this graph, "LMB" refers to Florida largemouth bass, and "Morone" refers to striped bass, white bass, and striped bass/white bass hybrids. Stocking data provided by FWC.

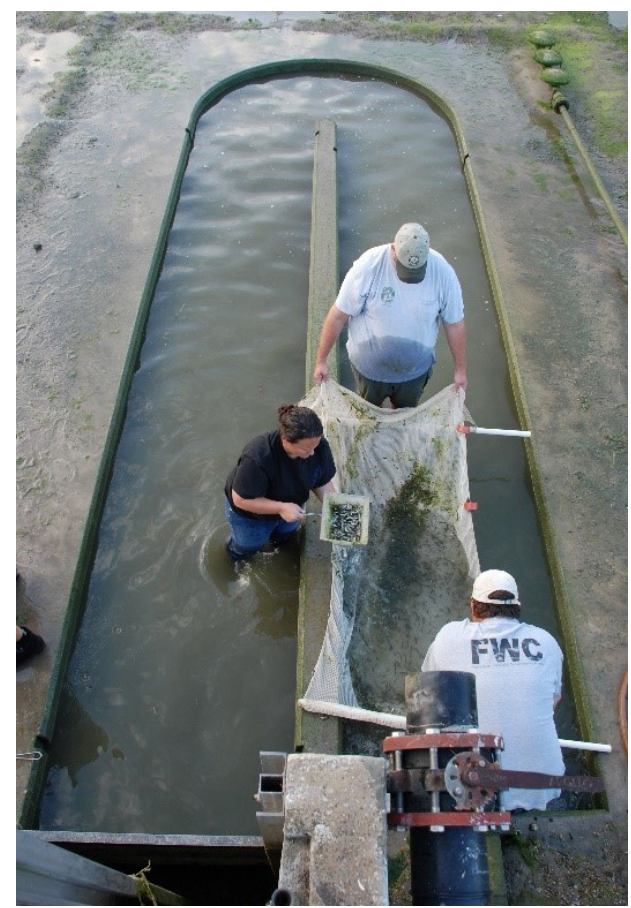

Figure 4. Workers at the Florida Bass Conservation Center collecting fish for stocking research.

Credits: Rick Stout

\section{Results and Discussion: What We Found}

\section{Requirements for Defining Stocking Success}

Developing a useful definition of stocking success is vital because it lays the foundation for:

1. defining the broad management goals,

2.identifying the specific management objectives that stocking is aiming to improve, and

3.identifying the processes by which stocking actions can affect management objectives and goals.
Understanding these management goals will allow for the creation of reasonable definitions of stocking success that are immediately practical to management agencies.

\section{Management Goals and Decisions Science}

The foundation of good decision making in fisheries management is based on explicitly defined and measurable goals and objectives (Gislason et al. 2000). Explicit management goals and objectives (for example, "increase fishing catch rates by $10 \%$ ") allow success to be easily measured, but vague goals like "provide good fishing opportunities" make it difficult to objectively evaluate or compare the success of any management action, including stocking (Trushenski et al. 2014). Goals and objectives that relate to quantifiable metrics are preferred-things like wild-spawning biomass, fishing mortality rate or fishing effort/participation (Camp et al. 2013). Sometimes explicit and measurable management objectives are specified for recreational fisheries, but this is not always the case (Cowx et al. 2010). In Florida, there are strategic plans for FWC in general, but currently there is not a strategic freshwater recreational fisheries plan that includes quantifiable objectives. Until these objectives are made explicit by agencies, it may be best to consider the management objectives most commonly used in other recreational fisheries, as described in scientific literature (Camp et al. 2013).

\section{Objectives Relevant to Stocked Recreational Fisheries}

Biological objectives of recreational fisheries are the most well-known. Common objectives, for instance, include preventing overfishing or sustaining fish populations. Overfishing leading to fish population decline is a concern in some freshwater recreational fisheries (Post et al. 2002), but in Florida, many fisheries have so much voluntary catch and release behavior that overfishing is less of a concern (Myers et al. 2008). Other common biological objectives that are likely relevant to Florida include ensuring there is suitable fish habitat and that wild fish populations are not adversely affected by diseases or by the introduction of deleterious genetic traits. The latter is particularly important for defining stocking success.

Increasingly, it is recognized that recreational fisheries should be managed for socioeconomic objectives in addition to biological objectives (Radomski et al. 2001; Cowx et al. 2010). There are multiple categories of these socioeconomic objectives: consumer welfare (economic value) and market activity (economic impact) (Propst and Gavrilis 1987). Consumer welfare (sometimes called consumer surplus) is one benefit fishing provides to society. 
Consumer welfare is related to things like anglers' psychological satisfaction with fishing experiences (Arlinghaus 2006). Value- or satisfaction-related objectives are usually measured with economic models and surveys that help describe how much anglers value fishing experiences or specific attributes of fishing like catch rate or size. On the other hand, market activity-sometimes called economic impact-describes how money is spent associated with an activity, like fishing. Market activity is usually important to local businesses and governments that directly benefit from fishing-related expenditures, and especially from money brought from outside to inside their counties or states. Since this market activity depends on expenditures made for fishing, it is usually positively related to fishing efforti.e., more fishing trips or license purchases will usually result in greater market activity. Both value/satisfaction and market activity/impact are relevant to stocking.

Most recreational fisheries stock-enhancement objectives, even if not explicitly described, will include these three things:

1. Sustain and do not harm wild fish populations, related to metrics like population abundance, recruiting of young fish, fishing mortality rates, fish health, and adequate genetic diversity.

2. Sustain or increase market activity, especially of certain regions, related to metrics such as overall fishing effort (number of trips), fishing license sales, and fishing-related expenditures.

3. Sustain or increase socioeconomic value, related to metrics like angler satisfaction with fishing and fishing attributes such as catch rates, catch size, fishing facilities, etc.

\section{How Stocking Can Affect Recreational Fishing Objectives}

Stocking can affect common recreational fishing objectives through two general pathways (Figure 4). The first pathway-the physical/fisheries pathway-is indirect but probably the most commonly considered. For the physical/fisheries pathway, stocking first must improve fish populations, usually by increasing fish abundance, size, or availability to anglers. Then the improved fish populations must improve fishery metrics like catch rates or total fishing effort. Finally, these fishery changes need to increase socioeconomic value by increasing satisfaction, and/or increase market activity by augmenting expenditures. Critically, the changes must achieve these objectives without hurting wild fish populations.
Increasing angler satisfaction and/or economic impact can be achieved by different stocking "methods." Stock enhancement (the stocking of hatchery-reared fish to an existing wild population) can increase catchable abundance of fish, but usually when the fish are stocked at larger sizes. Also, for some species, like largemouth bass, increased abundance from stock enhancement has been difficult to consistently demonstrate. Alternatively, "restocking"-placing hatchery-raised fish in depleted or newly created waters that have no or very few fish-may produce more easily detectable improvement in socioeconomic metrics by quickly restoring fisheries. Finally, "introduction stocking" (introducing new or not naturally occurring fish) or "put-and-take stocking" (where fish are stocked annually or semi-annually to provide temporary fisheries in waters where self-reproducing populations are limited) may most notably increase fish populations leading to socioeconomic objectives. In Florida, an example of introduction stocking includes stocking striped bass and striped bass hybrids into lakes and reservoirs, while a common put-and-take fishery is stocking channel catfish into ponds. Both these types of stocking can create fisheries where none previously existed and are some of the most potent tools for improving angler satisfaction and/or economic impact, though introduction stocking also may have greater ecological risks if introduced fish harm native populations.

Possibly the greater challenge is increasing the socioeconomic objectives without hurting wild fish populations. Stocking can sometimes have unintended, deleterious effects on wild fish populations if stocked fish compete with wild fish, introduce less-fit genetics, or potentially spread diseases (Camp et al. 2017). This especially is the case with stock enhancement, because hatchery fish are not generally the genetic equivalent of wild fish. Hatchery fish may compete with or possibly replace wild fish. In these situations, fish populations may not be sufficiently augmented so that angler satisfaction increases. Also, if stocking does increase the overall fish population, it is possible that this greater density may depress growth rates, and anglers may be disappointed with their trophy fish catches. There can be unforeseen detriments even to the best-case scenario, in which wild fish are unaffected by hatchery fish and the total population is increased. The larger population and initially better angling could result in a greater fishing effort that could exert more intense fishing mortality on wild populations. For these reasons it is preferable to use stocking in ways that minimize the effects on wild fish (like re-stocking, put-and-take, some introduction stocking), and to enhance wild populations primarily when there is little concern of overfishing. Luckily, this is often the case in 
Florida largemouth bass fisheries, owing to the high rate of catch-and-release angling (Myers et al. 2008).

The direct psychological/non-fisheries path (Figure 5) is less often considered but may be especially intuitive to managers. This path requires that anglers have a prior belief that stocking programs are "good." With a positive outlook on stocking, anglers may attain greater satisfaction simply from knowing that hatcheries and stocking programs exist, regardless of how these stocking programs actually influence fish populations (Camp et al. 2017). This path is possible due to the consistently great popularity of stocking programs with stakeholders, but also because stocking programs can create additional benefits. For example, fish hatcheries can serve as public outreach and education facilities, allowing stakeholders not just a chance to see fish, but also to understand how much work must go into stocking fish. With careful messaging, this may even translate into greater stakeholder appreciation for naturally reproducing fish populations, though this has not been well studied.

\section{How should success of stocking be defined?}

Given all of this, how should management agencies define and gauge the relative success of stocking programs? We provide some suggestions:

\section{- Defining stocking success depends on recreational} Psychological/ non-fisheries path

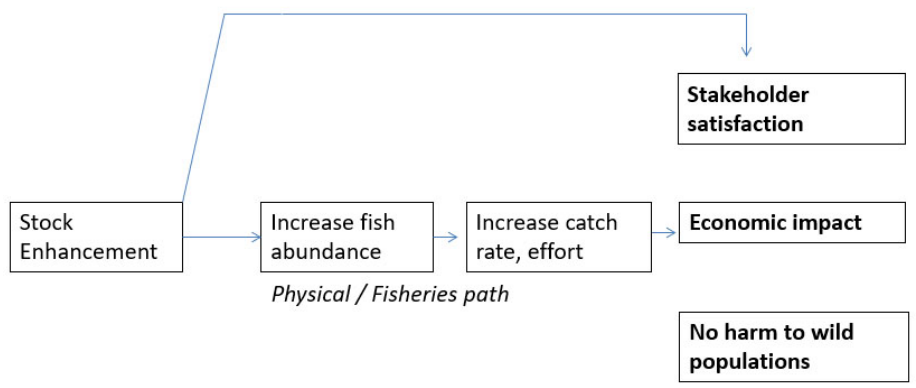

Figure 5. The two possible pathways for successful stocking.

fisheries management objectives. Agencies must define what exactly they want to achieve with stocking at state, region, and perhaps even water-body levels to be able to understand how successful stocking programs are.

- Successful stocking should not incur biological or ecological harm to sensitive populations. We consider this a requirement that should not be used to define when stocking is successful-a stocking operation that doesn't incur harm to sensitive populations will not necessarily be successful-but rather one that may be used to identify clearly unsuccessful stocking-a stocking operation that does incur harm to sensitive populations is necessarily unsuccessful, whether or not it achieves other objectives. In practice, concerns of biological harm from stocking should be addressed at a planning stage and used to prioritize stocking efforts towards fisheries where biologi$\mathrm{cal} /$ ecological concerns are minimal and socioeconomic objectives have substantial potential for being increased.

- Assessing stocking success should include socioeconomic metrics and objectives. Some of the most important metrics will relate to angler satisfaction with fishing and fisheries management, as well as overall angling participation, effort, and license sales. These metrics may be measured at the state level but may be particularly meaningful when evaluated for particular regions or even demographics of management interest (e.g., angling participation in urban and suburban areas).

- Often, successful stocking will increase availability of fish to anglers. Increasing availability of fish to anglers will sometimes mean increasing existing populations of fish with stock enhancement. But greater and more detectable effects often are found when hatchery fish are used in restocking or introduction stocking, including put-and-take stocking. All these cases, however, require a reasonable proportion of fish to survive long enough following stocking to eventually be caught by anglers.

- Stocking can be successful even if it does not dramatically change fish populations. Where stocking is popular with stakeholders, the simple existence of a program may provide benefits. Additional benefits from stocking may be realized by designing and marketing hatcheries as multi-purpose facilities that emphasize public outreach, such as through tours, education events, and potentially even fishing ponds.

\section{What are practical next steps for recreational fisheries management agencies?}

We outline a process that a state recreational fisheries management agency might follow to develop a specific definition of successful stocking and process for evaluating stocking success that is tailored to that agency's stakeholders, needs, and resources.

1. Assess, clarify, and prioritize management objectives if they do not already exist. This process probably should involve stakeholder input to both ensure end-users (anglers and non-angling public) are well-served, and also to realistically reflect pressures on management agencies. Pressure may come from anglers, but also from other stakeholders-especially those in local, county, and state governance institutions. Surveys are useful to 
identify angler stakeholder preferences, while manager and expert opinion might describe political stakeholders' desires.

\section{Identify which objectives stocking can best address.}

The most successful stocking programs will use stocking judiciously where it can outperform other management actions (like habitat restoration, outreach, etc.). It is necessary to both understand what stocking and other management options are, and also to gauge potential ecological and socioeconomic responses to these actions. This may be addressed by working groups consisting of agency personnel, scientists, and stakeholders. Fisheries and hatchery managers can identify feasible actions and help scientists integrate literature and data to develop conceptual and quantitative models for predicting fishery outcomes. Predictions may benefit from additional stakeholder surveys intended to understand how certain anglers would behave under different scenarios, from long-term data synthesis, and from small-scale field experiments.

\section{Develop a strategic stocking plan. A strategic stock-} ing plan should describe specifically how selected management objectives can be achieved with stocking given hatchery resources. A strategic plan should blend information gathered in the previous steps with critical information from hatchery managers regarding rearing and stocking capabilities and possibilities. Likely there will be some uncertainty regarding how and to what extent stocking affects fisheries, and how stakeholder preferences and management resources may change over time. Therefore, it is best to plan regular re-evaluations of the strategic plan that update stocking knowledge, resource constraints, stakeholder preferences, and prioritized management needs. The most critical part of a strategic stocking plan is linking specific and feasible stocking actions to the intended management objectives listed in step 2 (above). The capacity of stocking to achieve these outcomes represents how successful stocking is. That a strategic stocking approach should be updated over time emphasizes that the definition of stocking success must also be updated. While there is no absolute definition of stocking success, there is a process to define it for a place and time, and this is of greatest utility to recreational fisheries management agencies.

\section{Beyond defining stocking success.}

The best-designed definitions of stocking success will be of limited utility without monitoring to determine how successful stocking actually is. Most recent works on hatcheries, stocking, and management in general describe the critical importance of monitoring, including recent wide-reaching AFS guidelines on hatchery operations (Treshinski et al. 2014). The monitoring of stocking should be designed in accordance with the definition of stocking success, and therefore the fisheries management objectives. With this process in place, it is likely that stocking monitoring will extend well beyond measuring survival of stocked fish, percent contribution, or detecting any deleterious effects on wild fish and should include socioeconomic metrics like angler satisfaction, effort, and participation.

If this process for defining stocking success is executed with foresight and intent, it will likely produce additional benefits. Explicit and measurable objectives for recreational fisheries management can improve agency-wide decisionmaking, as can better understanding of stakeholder preferences. This approach is also designed to be imminently compatible with two of the most commonly-desired types of management-active adaptive management and cooperative, place-based management. Active adaptive management requires designing, implementing, and evaluating effects of management actions as if they were experiments. Stocking is an ideal management action for active adaptive management because it almost always involves replication across different water bodies, often for many years. Thus, defining fishery objectives and metrics for stocking success, followed by monitoring, can promote advanced learning - not only of the effects of stocking, but also of ecological and socioeconomic processes and how these are linked. Cooperative, place-based management usually refers to actively involving local stakeholders in management decision-making-something many management agencies are increasingly interested in doing. This might be well-achieved with stocking if agencies plan to include local stakeholders in decisions about which fish species and sizes are stocked in which waters. These opportunities to combine stocking with adaptive and cooperative management are important because learning and stakeholder involvement have consistently been described as important prerequisites for making recreational fisheries more resilient and allowing fisheries systems to resist or rebound quickly from unpredictable but unavoidable future perturbations. 


\section{References}

Arlinghaus, R. 2006. "On the apparently striking disconnect between motivation and satisfaction in recreational fishing: the case of catch orientation of German anglers." North American Journal of Fisheries Management, 26(3): 592-605. https://doi.org/10.1577/M04-220.1

Bert, T. M., C. R. Crawford, M. D. Tringali, S. Seyoum, J. L. Galvin, M. Higham, and C. Lund. 2007. "Genetic management of hatchery-based stock enhancement." In Ecological and genetic implications of aquaculture activities (pp. 123-174). Springer, Dordrecht.

Camp, E. V., K. Lorenzen, R. N. Ahrens, L. Barbieri, and K. M. Leber. 2013. "Potentials and limitations of stock enhancement in marine recreational fisheries systems: an integrative review of Florida's red drum enhancement." Reviews in Fisheries Science 21 (3-4): 388-402. https://doi.or $\mathrm{g} / 10.1080 / 10641262.2013 .838075$

Camp, E. V., K. Lorenzen, R. N. M. Ahrens, and M. S. Allen. 2014. "Stock enhancement to address multiple recreational fisheries objectives: an integrated model applied to red drum Sciaenops ocellatus in Florida." Journal of fish biology 85 (6): 1868-1889. https://doi.org/10.1111/jfb.12548

Camp, E. V., S. L. Larkin, R. N. Ahrens, and K. Lorenzen. 2017. "Trade-offs between socioeconomic and conservation management objectives in stock enhancement of marine recreational fisheries." Fisheries research 186 446-459. https://doi.org/10.1016/j.fishres.2016.05.031

Cowx, I. G., R. Arlinghaus, and S. J. Cooke. 2010. "Harmonizing recreational fisheries and conservation objectives for aquatic biodiversity in inland waters." Journal of Fish Biology 76 (9): 2194-2215. https://doi. org/10.1111/j.1095-8649.2010.02686.x

Gislason, H., M. Sinclair, K. Sainsbury, and R. O’boyle. 2000. "Symposium overview: incorporating ecosystem objectives within fisheries management." ICES Journal of Marine Science 57 (3): 468-475. https://doi.org/10.1006/ jmsc.2000.0741

Lorenzen, K. 2005. "Population dynamics and potential of fisheries stock enhancement: practical theory for assessment and policy analysis." Philosophical Transactions of the Royal Society of London B: Biological Sciences 360 (1453): 171-189. https://doi.org/10.1098/rstb.2004.1570
Lorenzen, K. 2014. "Understanding and managing enhancements: why fisheries scientists should care." Journal of Fish Biology 85 (6): 1807-1829. https://doi.org/10.1111/ jfb. 12573

Myers, R., J. Taylor, M. Allen, and T. F. Bonvechio. 2008. Temporal trends in voluntary release of largemouth bass. North American Journal of Fisheries Management 28 (2): 428-433. https://doi.org/10.1577/M06-265.1

Pereira, D. L., and M. J. Hansen. 2003. "A perspective on challenges to recreational fisheries management: summary of the symposium on active management of recreational fisheries." North American Journal of Fisheries Management 23 (4): 1276-1282. https://doi.org/10.1577/M01-234

Propst, D. B., and D. G. Gavrilis. 1987. "Role of economic impact assessment procedures in recreational fisheries management." Transactions of the American Fisheries Society 116 (3): 450-460. https://doi. org/10.1577/1548-8659(1987)116<450:ROEIAP >2.0.CO;2

Radomski, P. J., G. C. Grant, P. C. Jacobson, and M. F. Cook. 2001. "Visions for recreational fishing regulations." Fisheries 26 (5): 7-18. https://doi. org/10.1577/1548-8446(2001)026<0007:VFRFR>2.0.CO;2

Tringali, M. D., and T. M. Bert. 1998. "Risk to genetic effective population size should be an important consideration in fish stock-enhancement programs." Bulletin of Marine Science 62 (2): 641-659.

Trushenski, J., L. Blankenship, J. Bowker, T. Flagg, J. Hesse, K. Leber, K. Lorenzen et al. 2014. "AFS completes assessment, issues new guidance regarding hatchery operation and the use of hatchery-origin fish." Fisheries 39 (11): 543-547 https://doi.org/10.1080/03632415.2014.964395

Walters, C. J., and S. J. Martell. 2004. Fisheries ecology and management. Princeton University Press. 